\title{
0365 ETHANOL POWERED APPLIANCES: THE FRENCH APPROACH TO IMPROVE THEIR SAFETY
}

F Weil, Y Peter* Correspondence: General Directorate for Competition Policy, Consumer Affairs and Fraud Control (DGCCRF), Bureau E2 59, Boulevard Vincent Auriol PARIS, 75703 CEDEX 13, France

\subsection{6/ip.2010.029215.365}

Ethanol powered appliances (EPA) are usually marketed in a rather up-market position. In France, these products were marketed at low prices from the beginning, and the number of sales grew rapidly, whereas the safety of these devices was a concern. Accordingly, the DGCCRF (French national market surveillance authority) gave an impetus in 2006-2007 for the professionals to have their appliances certified, and to start a Standardisation Committee within the AFNOR. Several events an accident, a study from the Consumer Safety Commission (CSC) highlighting EPA as hazardous as regards burn, fire and intoxication hazards, and media campaign - made the DGCCRF quicken the pace of its actions in order to improve their safety:

The professionals were reminded in the Economy Ministry Recommendation published in the French Republic Official Journal (November 2008) that their products had to meet the general safety requirement;

A survey was launched in order to have a comprehensive overview of operators and their products, and analyse the safety level of each appliance.

It was decided to create a Select Committee within the AFNOR Standardisation Committee composed with the DGCCRF, CSC, LNE (national laboratory of conformance-testing) and other Administrations (Health, Housing, Fire Safety). As a result, the French standard NF D 35-386 (Ethanol-fired appliances Safety requirements and test methods), whose specificity is to integrate fail-safe devices, has been published in August 2009. France is now willing to promote this standard internationally. This is an example of the French approach bringing stakeholders together for a common goal. 